\title{
A very low thymus function identifies patients with substantial increased risk for long-term mortality after kidney transplantation
}

\author{
Michiel G. H. Betjes ${ }^{1 *}$ D, Anton W. Langerak², Mariska Klepper ${ }^{1}$ and Nicolle H. R. Litjens ${ }^{1}$
}

\begin{abstract}
Background: End-stage renal disease is associated with premature ageing of the $T$ cell immune system but interindividual variation is substantial. The hypothesis was tested that advanced immunological T cell ageing assessed by peripheral T cell differentiation increases the long-term mortality risk after renal transplantation.

Results: Circulating T cells of 211 recipients of a kidney from a living donor were analyzed before and in the first year after transplantation. The number of CD31-positive naive T cells (as a marker for recent thymic emigrants) and the differentiation status of the memory T cells was assessed. Thirty recipients died during follow-up of at least 5 years. Absolute numbers of naive CD4 ${ }^{+}$(living:258 cells/ $\mu$ lvs. deceased:101 cells $/ \mu \mathrm{l}, p<0.001$ ) and naive CD8 ${ }^{+} T$

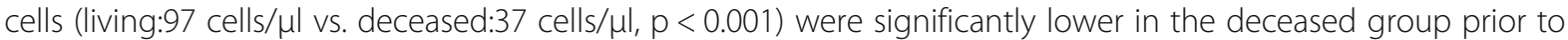
transplantation. In a multivariate proportional hazard analysis the number of naive $\mathrm{CD}^{+} \mathrm{T}$ cells remained associated with all-cause mortality (HR 0.98, $\mathrm{Cl} 0.98-0.99, p<0.001)$. The low number of naive $\mathrm{T}$ cells in the deceased patient group was primarily caused by a decrease in recent thymic emigrants (i.e. less $C D 31^{+}$naive $T$ cells) indicating a lowered thymus function. In addition, the physiological age-related compensatory increase in CD31- naïve T cells was not observed. Within the first year after transplantation, the number and characteristics of naive T cells remained stable.
\end{abstract}

Conclusions: A severe reduction in circulating naive T cells because of a decrease in recent thymic emigrants is highly associated with all-cause mortality after renal transplantation.

Keywords: Kidney transplantation, Mortality, Premature ageing, Thymus, naïve T cells;recent thymic emigrants

\section{Background}

Progressive loss of renal function leading to end-stage renal disease (ESRD) is associated with premature ageing of the T-cell system. The pro-inflammatory environment resulting from loss of renal function [1] is marked by a lower thymic output, increased T-cell differentiation, telomere shortening and skewing of the $\mathrm{T}$ cell receptor (TCR) repertoire [2-4].

\footnotetext{
* Correspondence: m.g.h.betjes@erasmusmc.nl.

'Department of Internal Medicine, section Nephrology and Transplantation, Erasmus MC, University Medical Centre, Rotterdam, the Netherlands

Full list of author information is available at the end of the article
}

The changes in the peripheral T-cell compartment of ESRD patients resemble the physiological changes in the immune system of healthy elderly individuals with the immunological age of ESRD patients on average being increased by $15-20$ years compared to their chronological T-cell age [4-6].

One of the most consistent and prominent features of ESRD-related premature aging is a lowered thymic output. This is characterized by a decreased number in newly formed naive $\mathrm{T}$ cells (i.e. recent thymic emigrants (RTE)) in the circulation. These RTE can either be recognized by the presence of $\mathrm{T}$ cell receptor excision circles (circular DNA remnants of the TCR gene rearrangement during thymic maturation) or CD31 expression on naïve $\mathrm{CD} 4 \mathrm{~T}$ 
cells, and close correlation exists between both assays in healthy controls and ESRD patients [4, 7]. As the number of differentiated memory $\mathrm{T}$ cells increases with age, both mechanisms together reduce the percentage of naive $\mathrm{T}$ cells in the circulation to a relatively high extent $[4,8,9]$. Furthermore, the increased proliferation and differentiation reduces the $\mathrm{T}$-cell telomere length and increases skewing of the TCR repertoire $[2,3]$.

The driving force behind ESRD-related premature ageing is believed to be the pro-inflammatory environment that arises with retention of uremic waste products, which leads to increased oxidative stress and inflammation $[1,6,10]$. The prematurely aged $\mathrm{T}$ cell system of ESRD patients is associated with a reduced vaccination response [11-14] and an increased infection susceptibility [15]. After renal transplantation (RT), increased numbers of highly differentiated $\mathrm{T}$ cells are associated with a decreased risk for early acute rejection [16].

Currently, it is not known whether parameters of a prematurely aged T-cell system in ESRD patients are associated with long term survival. In this study, we investigated the association between thymic output measured by CD31 positive naïve CD4 T cells and T-cell differentiation status in recipients prior to renal transplantation with all-cause mortality at follow-up.

\section{Results}

\section{Recipients characteristics and all-cause mortality}

Recipients characteristics are shown in Table 1. The median patient age was 57 years and the majority of the recipients (91\%) underwent a renal transplantation for the first time. Thirty recipients (median age 63 year, range 26-78) deceased at a median of 40 months after transplantation (range 6-74 months). The percentage of patients receiving high dose steroids and/or T cell depleting therapy for acute rejection was not significantly different between the living and deceased recipient group (data not shown).

\section{Pre-transplant $\mathrm{T}$ cell ageing parameters and survival}

The average number of different $\mathrm{T}$ cell subsets is shown in Table 2.

The deceased recipient group had a significantly lower total number of circulating $\mathrm{CD}^{+} \mathrm{T}$ cells as a result of decreased numbers of naïve $\mathrm{CD} 4^{+}$(Fig. 1A) and central-memory $\mathrm{T}$ cells. Also within the $\mathrm{CD} 8^{+} \mathrm{T}$ cell population the naïve $\mathrm{T}$ cells (Fig. 1A) were significantly decreased, but this was accompanied by an increase in the cell count of total and more differentiated subpopulations of memory $\mathrm{T}$ cells (effector memory and Temra subpopulations). As a result, the total number of $\mathrm{CD}^{+} \mathrm{T}$ cells was similar between the living and deceased group of recipients. Cell counts of naïve $\mathrm{CD} 4^{+}$ and $\mathrm{CD}^{+} \mathrm{T}$ cells were significantly correlated (Fig. 1B, Rs $=0.56, p<0.001)$.
Table 1 Clinical and demographical characteristics of renal allograft recipients $(n=211)$ prior to transplantation

\begin{tabular}{ll}
\hline Age in years, median (range) & $57(19-79)$ \\
\hline Male/female & $62-38 \%$ \\
Follow-up time in months, median (range) & $74(0-97)$ \\
Living kidney donor, $n$ (\%) & $211(100 \%)$ \\
Previous kidney transplant, $n$ (\%) & $19(9.0 \%)$ \\
Pre-emptive transplantation, $n$ (\%) & $91(43.1 \%)$ \\
Anti-rejection therapy & $39(18.4 \%)$ \\
T cell depleting therapy for rejection & $18(8.5 \%)$ \\
Cardiovascular disease prior to transplantation, $n$ (\%) & $53(25.1 \%)$ \\
Distribution of underlying kidney disease & \\
Nephrosclerosis/hypertension & $22.7 \%$ \\
Primary glomerulopathies & $13.7 \%$ \\
Diabetes mellitus & $19.9 \%$ \\
Urinary tract infections/ stones & $2.8 \%$ \\
Reflux nephropathy & $4.7 \%$ \\
Polycystic kidney disease & $19.0 \%$ \\
Other & $11.8 \%$ \\
Unknown & $5.2 \%$ \\
CMV seropositive* & $59 \%$ \\
Recipients deceased during follow-up & 30 \\
Cause of death & $23.3 \%$ \\
infection & \\
cancer & $26.0 \%$ \\
other & $3.3 \%$ \\
\hline & \\
& \\
&
\end{tabular}

The number of naïve $T$ cells showed a progressive decreases with age in both healthy individuals and ESRD patients. Confirming data of a previous publication [4], these numbers are on average significantly lowered at all decades in the ESRD patient group leading to a biological age difference of 20 years (Fig. 2). However, at every decade the average number of naïve $\mathrm{CD}^{+}$and $\mathrm{CD}^{+} \mathrm{T}$ cells was lower in the deceased recipient group compared with the living recipient group.

Multivariate proportional hazard logistic regression analysis (Table 4) confirmed that independent of age, a lower number of either $\mathrm{CD}_{4}^{+}$(HR 0.99, 95\% CI 0.98-0.99, $p<$ 0.0001 ) or $\mathrm{CD}^{+}$naive T cells (HR $0.98,95 \%$ CI $0.96-0.99$, $p<0.001$ ) was significantly associated with all-cause mortality. When combining both $\mathrm{CD} 4^{+}$and $\mathrm{CD} 8^{+}$naïve $\mathrm{T}$ cell numbers in the model, only the number of naïve $\mathrm{CD} 4^{+} \mathrm{T}$ cells remained significantly associated with all-cause mortality at follow-up (HR 0.99, 95\% CI 0.98-0.99, p < 0.001). The interaction term for $\mathrm{CD}^{+}$and $\mathrm{CD}^{+}$naïve $\mathrm{T}$ cell was not statistically significant (not shown). As expected, similar 
Table 2 Immunological T cell parameters of renal allograft recipients prior to transplantation

\begin{tabular}{|c|c|c|c|}
\hline & Alive $(n=181)^{*}$ & Deceased $(n=30)^{*}$ & $p$-value \\
\hline Total CD4 T cells & $720(418)^{* *}$ & $404(203)$ & 0.001 \\
\hline Naive CD4 T cells & $207(233)$ & $94(78)$ & $<0.001$ \\
\hline Naïve CD4 CD31 pos T cells & $119(156)$ & $59(59)$ & $<0.001$ \\
\hline Naive CD4 CD31neg T cells & $66(84)$ & $35(35)$ & $<0.001$ \\
\hline Memory CD4 T cells & $471(273)$ & $321(205)$ & 0.018 \\
\hline Central memory CD4 T cells & $289(223)$ & $169(147)$ & 0.004 \\
\hline Effector memory CD4 T cells & $155(124)$ & $117(153)$ & 0.4 \\
\hline Temra CD4 T cells & $10(17)$ & $7(11)$ & 0.1 \\
\hline CD28null memory CD4 T cells & $16(53)$ & $25(69)$ & 0.4 \\
\hline Total CD8 T cells & $356(231)$ & $381(565)$ & 0.3 \\
\hline Naïve CD8 T cells & $67(91)$ & $27(35)$ & $<0.001$ \\
\hline Naïve CD8 CD31 pos T cells & $64(89)$ & $26(30)$ & $<0.001$ \\
\hline Naive CD8 CD31neg T cells & $2(2)$ & $1(3)$ & 0.6 \\
\hline Memory CD8 T cells & $256(208)$ & $299(571)$ & 0.039 \\
\hline Central memory CD8 T cells & $16(21)$ & $14(15)$ & 0.7 \\
\hline Effector memory CD8 T cells & $109(94)$ & $125(214)$ & 0.2 \\
\hline Temra CD8 & 97 (153) & $149(340)$ & 0.2 \\
\hline CD28null memory CD8 T cells & $119(172)$ & $172(399)$ & 0.1 \\
\hline CD4/CD8 T cell ratio & $2.0(1.6)$ & $1.2(1.3)$ & 0.008 \\
\hline CMV seropositive $e^{* * *}$ & $57.8 \%$ & $66.7 \%$ & 0.6 \\
\hline
\end{tabular}

*Recipients alive and deceased at time of follow-up, ${ }^{* *}$ cell numbers are expressed in cells/ $\mu \mathrm{L}$ in medians with interquartile range between parenthesis, ***percentage of recipients with detectable serum anti-cytomegalovirus antibodies

results were obtained using CD31pos naïve $\mathrm{T}$ cells instead of total naïve $\mathrm{T}$ cell as a variable in the logistic regression analysis (data not shown).

A positive CMV serostatus is an independent factor associated with a (modest) decreased number of circulating naïve $\mathrm{T}$ cells in ESRD patients [17]. This effect was also observed in the current cohort of patients, but independent of CMV serostatus the group alive at follow up had almost twice as much naïve $\mathrm{T}$ cells (and CD31pos naïve $\mathrm{T}$ cells) as the deceased group (Additional file 1: Table S1). Uni- and multivariate statistical analysis also did not show a significant relation between a CMV positive serostatus and mortality after transplantation (Tables 3 and 4).

\section{Naive T cells and the CD4/CD8 ratio}

Several studies have shown that an inverted CD4/CD8 $\mathrm{T}$-cell ratio is associated with immunological ageing and associated with poor survival $[18,19]$. An important contributor to this inverted ratio is CMV-seropositivity $[20,21]$. In our patient group, the CD4/CD8 T-cell ratio was highly associated with all-cause mortality (Tables 2 , 3 and 4), primarily as a consequence of a decreased $\mathrm{CD}^{+} \mathrm{T}$ cell count in the deceased recipient group compared to the living recipient group. This effect could not be contributed to the influence of CMV-seropositivity as this was equally distributed between both groups (deceased $66.7 \%$ vs living 57.8\%, $p=0.6$ ). In fact, CMVseropositive recipients on average showed a significantly decreased CD4/CD8 T-cell ratio $\left(\mathrm{CMV}^{+}\right.$vs. $\mathrm{CMV}^{-}$recipients: 1.85 vs $2.91, p<0.0001)$. This is because CMV infection leads to a substantial and persisting increase in numbers of circulating $\mathrm{CD}^{+}$memory $\mathrm{T}$ cells [22]. Thus, the decrease in CD4/CD8 T-cell ratio in the deceased recipients group was observed independently of CMVserostatus (data not shown).

\section{CD31 expression on naïve T cells and survival}

Expression of CD31 on naïve CD4 T cells can be used as a marker for recent thymic emigrants both in healthy individuals and ESRD patients and correlates very closely with results obtained by assaying the $\mathrm{T}$ cell receptor excision content $[4,23,24]$. Numbers of $C D 31^{+}$and $C D 31^{-}$naïve $\mathrm{CD}^{+} \mathrm{T}$ cells were significantly lower in the deceased recipient group compared to the living recipient group (Table 2). They remained significantly associated with allcause death including clinical parameters such as age as a variable in the proportional hazard regression analysis

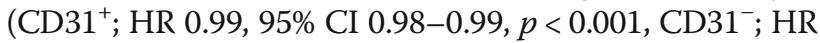
0.98, 95\% CI 0.97-0.99, $p=0.002$ ).

Similar to healthy controls $(n=239)$, the number of $\mathrm{CD}^{+}{ }^{+} \mathrm{CD} 31^{+}$naïve $\mathrm{T}$ cells in the living recipient group declined with age while the number of $\mathrm{CD} 31^{-}$naïve $\mathrm{T}$ 


\section{naive T cells}

\section{A}
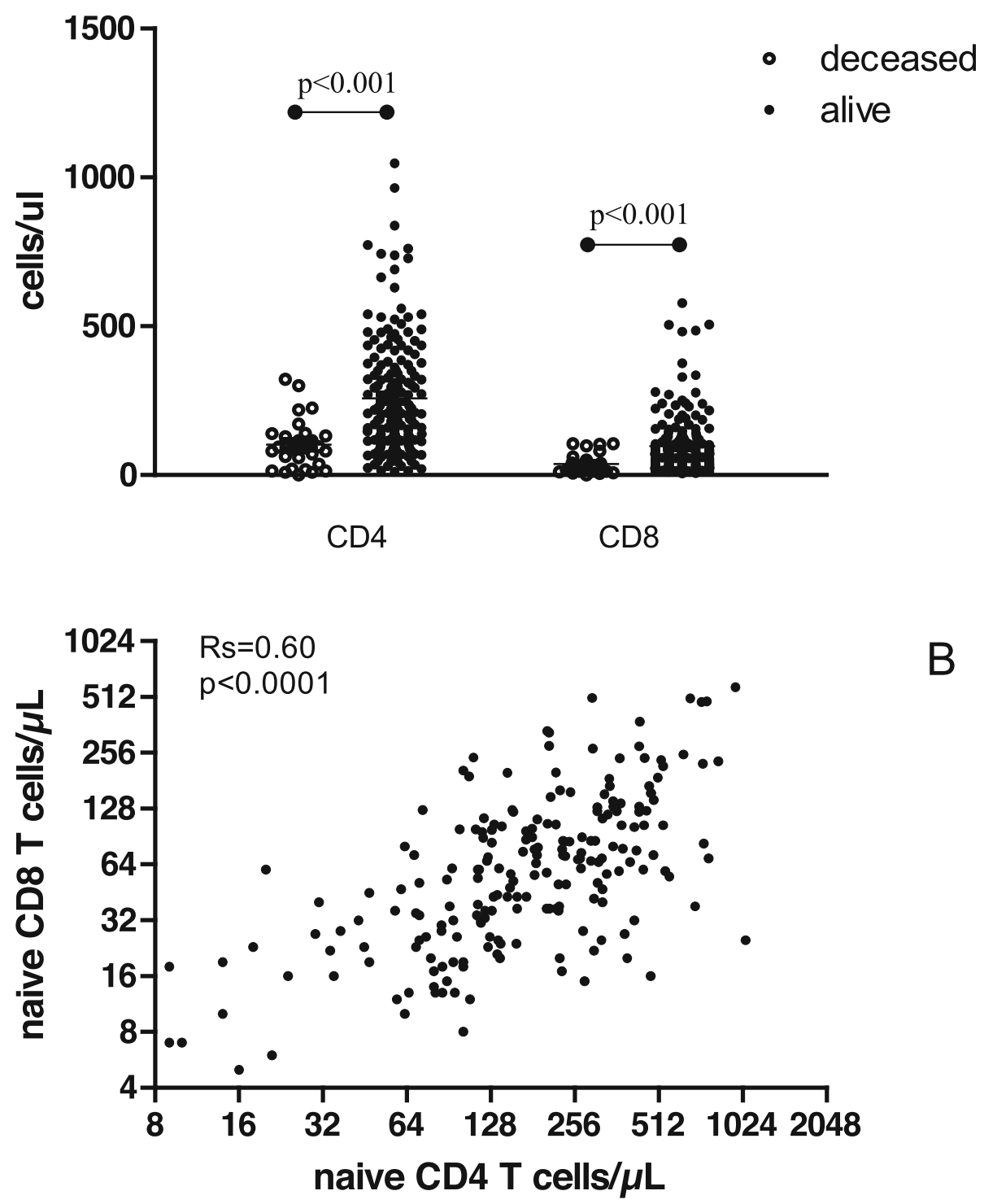

Fig. 1 Naïve T cells in relation to recipient survival after transplantation. Recipient's numbers of naïve $C D 4^{+}$and $C D 8^{+} T$ cells at the time of kidney transplantation divided in the recipients alive and deceased at time of follow-up (a). In the lower graph the correlation (Rs, Spearman rank correlation coefficient) between naïve $\mathrm{CD} 4^{+}$and $\mathrm{CD} 8^{+} \mathrm{T}$ cells numbers is shown (b)

cells increased and (partly) compensated for this decline (Fig. 2). From the age of 70 the average number of $\mathrm{CD} 31^{+}$and $\mathrm{CD}^{-} 1^{-}$contributed roughly equally to the composition of the circulating naïve $\mathrm{CD} 4^{+} \mathrm{T}$ cells.

In contrast, in the deceased recipient group this agedependent dynamics was not observed and the number of $\mathrm{CD} 31^{+}$and $\mathrm{CD} 31^{-}$naïve $\mathrm{T}$ cells were low in all age decades (Fig. 2).

The number of naïve $\mathrm{CD}^{+} \mathrm{T}$ cells decreased sharply with age both in healthy individuals and the living recipient group. In contrast to the $\mathrm{CD} 4^{+}$naïve $\mathrm{T}$ cells, virtually all naïve $\mathrm{CD}^{+} \mathrm{T}$ cells express $\mathrm{CD} 31^{+}$(see Table 2) which is a known phenomenon and limits its use as a marker for recent thymic emigrants for $\mathrm{CD}^{+} \mathrm{T}$ cells [25].

Numbers of naïve $\mathrm{CD} 4^{+}$and $\mathrm{CD} 8^{+} \mathrm{T}$ cells did not correlate with any of the clinical and demographical characteristics as shown in Table 1, except for age.

Dynamics of naïve T cell numbers during the first year after transplantation

In both the deceased and living recipient group the numbers of naïve $\mathrm{CD} 4$ and $\mathrm{CD} 8 \mathrm{~T}$ cells remained stable during the first year after transplantation (Fig. 3). Also, longitudinal follow-up during the first year after transplantation 
naive $\mathrm{CD}^{+} \mathrm{T}$ cells

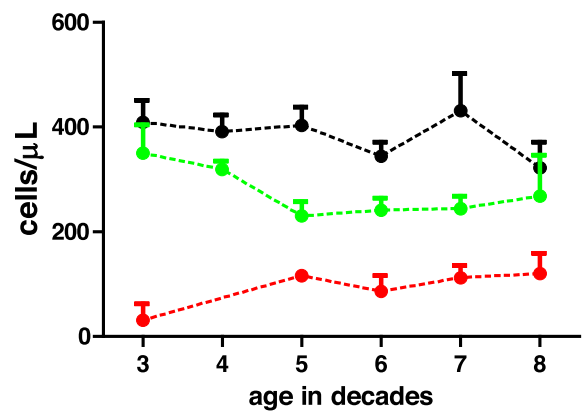

- healthy individuals $\bullet$ alive at FU naive $\mathrm{CD}^{+}{ }^{+} \mathrm{CD} 31^{+} \mathrm{T}$ cells

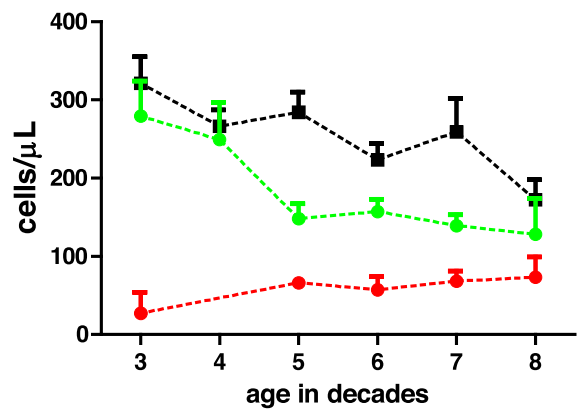

- deceased at FU
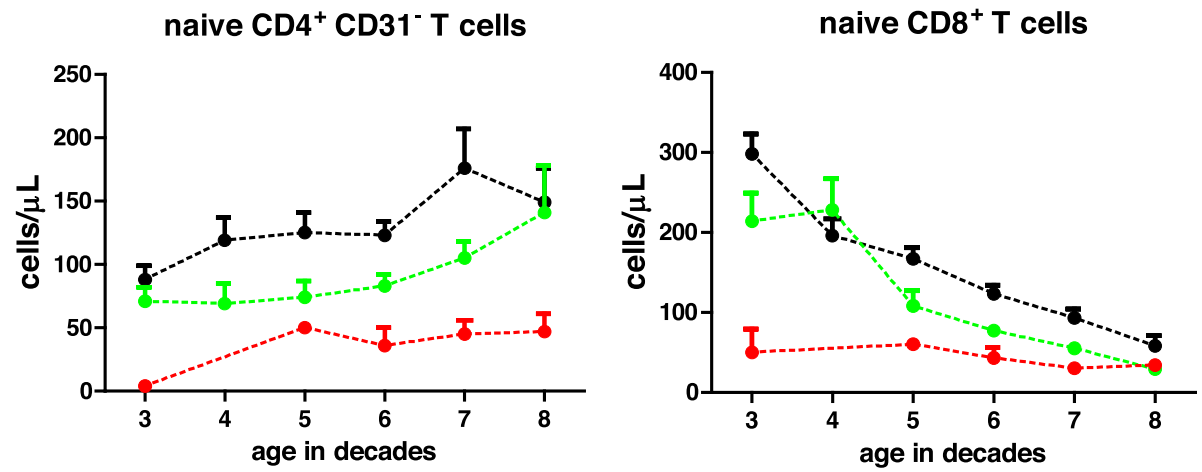

Fig. 2 Total number of naïve T cells and CD31 positive and negative CD4 ${ }^{+}$naïve $T$ cells in relation to age. Total nairve CD4 ${ }^{+}$, CD31 positive $\left(\mathrm{CD} 31^{+}\right)$and $\mathrm{CD} 31$ negative $\left(\mathrm{CD} 31^{-}\right)$naive $\mathrm{CD} 4^{+} \mathrm{T}$ cells and total naïve $\mathrm{CD} 8^{+} \mathrm{T}$ cells are shown for renal transplant recipients $(n=211)$ and healthy controls $(n=239)$. The cross-sectional data are represented in means with standard error of the mean for healthy controls (black dots), recipients alive (green dots) and deceased recipients at the time of follow-up (red dots). Age is shown in decades on the X-axis. Dashed interconnecting lines are added to facilitate interpretation of the graph

did not show significant changes in the number of CD31 ${ }^{+}$ and $\mathrm{CD} 31^{-} \mathrm{CD}^{+}$naïve $\mathrm{T}$ cells in both the deceased and living recipient group (Fig. 3).

\section{Discussion}

In this prospective study the hypothesis was tested that the degree of premature immunological aging at the time of renal transplantation is associated with long- term all-cause mortality thereafter. Of all immunological parameters tested, the number of circulating naïve $T$ cells was significantly associated with all-cause mortality at a follow-up of 5-7 years after transplantation. In particular, the number of $\mathrm{CD} 31^{+} \mathrm{CD} 4^{+}$naïve $\mathrm{T}$ cells was substantially lower in every age group in the deceased recipient group, without a compensatory increase in $\mathrm{CD} 31^{-} \mathrm{CD} 4^{+}$naïve $\mathrm{T}$ cells.

Table 3 Univariate Cox regression analysis for outcome death after transplantation

\begin{tabular}{llll}
\hline & HR & $95 \% \mathrm{Cl}$ & $\mathrm{p}$-value \\
\hline Male/female & 0.73 & $0.35-1.5$ & 0.39 \\
Age at transplantation (per year) & 1.05 & $1.02-1.09$ & 0.004 \\
Pre-emptive transplantation (no dialysis) & 0.24 & $0.09-0.64$ & 0.004 \\
Cardiovascular disease prior to transplantation & 3.18 & $1.55-6.52$ & 0.002 \\
Log C-reactive protein (mg/ml) & 2.51 & $1.26-4.98$ & 0.009 \\
Naive CD4 T cells (per cell/ul) & 0.99 & $0.98-0.99$ & $<.0001$ \\
Naïve CD8 T cells (per cell/ul) & 0.98 & $0.97-0.99$ & 0.001 \\
CD4/CD8 ratio & 0.57 & $0.38-0.86$ & 0.007 \\
CMV positive serostatus & 1.41 & $0.66-3.10$ & 0.36 \\
\hline
\end{tabular}


Table 4 Multivariate Cox regression analysis for outcome death after transplantation

\begin{tabular}{|c|c|c|c|}
\hline & Hazard ratio & $95 \% \mathrm{Cl}$ & $p$-value \\
\hline \multicolumn{4}{|l|}{ Multivariate model with CD4/CD8 ratio } \\
\hline Male sex & 0.36 & $0.16-0.78$ & 0.011 \\
\hline Age at transplantation (per year) & 1.07 & $1.03-1.11$ & $<.001$ \\
\hline Pre-emptive transplantation (no dialysis) & 0.25 & $0.09-0.70$ & 0.008 \\
\hline Cardiovascular disease prior to transplantation & 2.19 & $0.92-4.45$ & 0.08 \\
\hline Log C-reactive protein (mg/ml) & 1.82 & $0.83-3.97$ & 0.134 \\
\hline CD4/CD8 ratio & 0.57 & $0.37-0.86$ & 0.008 \\
\hline \multicolumn{4}{|l|}{ Multivariate model with CMV serostatus } \\
\hline Male sex & 0.40 & $0.18-0.86$ & 0.02 \\
\hline Age at transplantation (per year) & 1.06 & $1.02-1.1$ & 0.001 \\
\hline Pre-emptive transplantation (no dialysis) & 0.26 & $0.10-0.74$ & 0.010 \\
\hline Cardiovascular disease prior to transplantation & 1.76 & $0.81-3.81$ & 0.152 \\
\hline Log C-reactive protein (mg/ml) & 2.11 & $0.96-4.66$ & 0.064 \\
\hline CMV positive serostatus & 1.14 & $0.53-2.46$ & 0.73 \\
\hline \multicolumn{4}{|l|}{ Multivariate model with naïve CD4 T cells } \\
\hline Male sex & 0.29 & $0.28-0.66$ & 0.036 \\
\hline Age at transplantation (per year) & 1.06 & $1.02-1.09$ & 0.002 \\
\hline Pre-emptive transplantation & 0.25 & $0.09-0.68$ & 0.006 \\
\hline Cardiovascular disease prior to transplantation & 1.57 & $0.70-3.50$ & 0.27 \\
\hline Log C-reactive protein (mg/ml) & 1.81 & $0.83-4.84$ & 0.036 \\
\hline Naive CD4 T cells (per cell/ul) & 0.99 & $0.98-0.99$ & $<0.001$ \\
\hline \multicolumn{4}{|l|}{ Multivariate model with naïve CD8 T cells } \\
\hline Male sex & 0.42 & $0.19-0.92$ & 0.030 \\
\hline Age at transplantation (per year) & 1.04 & $0.99-1.07$ & 0.056 \\
\hline Pre-emptive transplantation & 0.26 & $0.09-0.68$ & 0.005 \\
\hline Cardiovascular disease prior to transplantation & 1.61 & $0.77-3.48$ & 0.22 \\
\hline Log C-reactive protein (mg/ml) & 2.09 & $1.01-4.33$ & 0.115 \\
\hline Naive CD8 T cells (per cell/ul) & 0.98 & $0.96-0.99$ & 0.006 \\
\hline
\end{tabular}

$\mathrm{CD}^{+} 1^{+}$naïve $\mathrm{T}$ cells are considered to be equivalent to naive $\mathrm{T}$ cells that have recently emigrated from the thymus and/or have not undergone prior TCR-induced proliferation. Although maybe not the perfect parameter, the number of $\mathrm{CD} 31^{+}$naïve $\mathrm{T}$ cells could be considered as an indicator of thymus function $[23,25]$. With increasing age the thymus involutes resulting in an almost linear decrease in $\mathrm{CD}_{31}{ }^{+} \mathrm{CD} 4^{+}$naïve $\mathrm{T}$ cells $[4,26]$. Specifically, the circulating naïve $\mathrm{CD}^{+} \mathrm{T}$ cell subset shrinks substantially [27] while the number of $\mathrm{CD} 31^{-} \mathrm{CD}^{+}$naïve $\mathrm{T}$ cells shows a compensatory increase [28]. This normal physiological ageing process is also observed in patients with chronic renal failure but their thymic output of naïve $\mathrm{T}$ cells, either measured by CD31 expression or content of TCR excision circles (TCR) $[7,26]$, shows premature biological ageing by $15-20$ years. This premature ageing of the thymus function was confirmed in this study and recipients most affected by immunological ageing, showing a severe decreased thymic output, appeared to have the highest mortality rate after transplantation. Currently, it is not known why some patients have such a low thymic output but low levels of interleukin 7 in ESRD patients may play a role [29]. A previous study showed that the decline in naive $\mathrm{T}$ cell numbers is associated with the progression of stage of renal insufficiency, indicative of a causative role for eGFR loss [29]. It is well-documented that patients with ESRD have a pro-inflammatory immune status [30]. Related to this phenomenon, activationinduced apoptosis of naïve T cells is higher in ESRD patients [4]. A shift from lymphoid to myeloid progenitor stem cells in the bone marrow, induced by inflammationassociated epigenetic changes, offers another possible explanation [1]. However, currently there are no studies that have tested these hypotheses in an experimental model.

The inter-individual variation of thymic output and decline over time is substantial both in ESRD patients and 
naive CD4 T cells

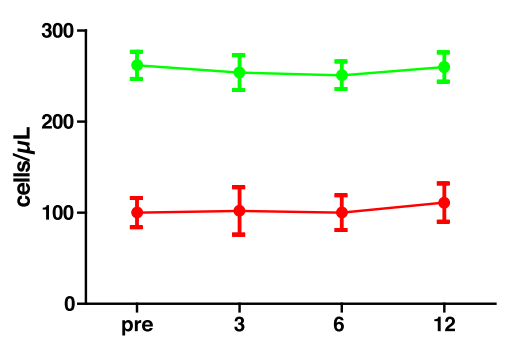

naive CD8 $\mathrm{T}$ cells

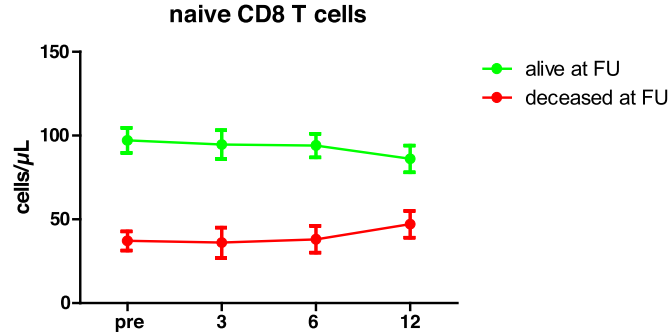

naive CD4 CD31+ T cells

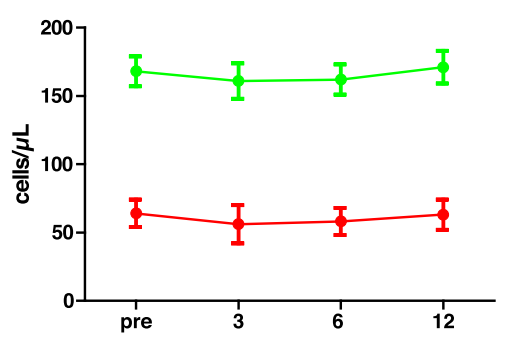

Fig. 3 Dynamics of naïve T cells post-transplantation. The longitudinal course of total $C D 4^{+}(A)$ and $C D 8^{+}(C)$ naïve $T$ cell numbers and the CD31expressing subset of naïve $\mathrm{CD} 4^{+} \mathrm{T}$ cells after renal transplantation are shown. On the $\mathrm{x}$-axis the time of sampling is shown: before transplantation $(0)$ and the months after transplantation $(3,6,12)$. Cell numbers are given in means with standard error of the mean forrecipients alive (green dots) and deceased recipients at the time of follow-up (red dots)

healthy individuals and ageing is the most prominent factor influencing this process. A positive CMV serostatus is associated with a (modest) decrease in numbers of naïve $\mathrm{T}$ cells but was not a confounding factor in this study.

The observation of a lack in compensatory increase of CD31- naive $\mathrm{T}$ cells in the deceased recipient group is intriguing but cannot be readily explained. In previous studies, an increased susceptibility for activation-induced cell death was identified as possible contributor to naïve $\mathrm{T}$ cell lymphopenia in ESRD patients [4, 9]. Although speculative, increased activation-induced cell death may be more prominently present in the deceased recipient group, e.g. because of a greater degree of systemic inflammation. As a general marker of systemic inflammation the serum $\mathrm{C}$-reactive protein concentrations were measured at time of $\mathrm{T}$ cell analysis but showed no relation with naïve $\mathrm{T}$ cell numbers (data not shown). However, in a recent study by Chiu et al. a significant correlation was observed between naïve CD8 $\mathrm{T}$ cell numbers and serum CRP level [8]. In that study virtually all patients were CMV seropositive which may indicate that $\mathrm{CMV}$, by causing increased systemic inflammation $[31,32]$, could induce naïve $\mathrm{T}$ cell depletion.

In ESRD patients, the reintroduction of adequate renal function by successful renal transplantation leads to a rapid normalization of uremia-associated inflammation and oxidative stress $[33,34]$. These processes are thought to underlie the impact of renal failure on the immune system but their reversal does not lead to a change of $\mathrm{T}$ cell ageing parameters [35]. However, we could not show a relation between early post-transplantation infection risk and e.g. low numbers of naïve $\mathrm{T}$ cells [36]. In the current study, the thymic output in both the deceased and living group of recipients remained remarkably stable, indicating that even the most severely affected patients do not even partially restore their thymic function.

In a previous study, it was shown that the number of circulating naïve $\mathrm{T}$ cells closely correlates with the content of naïve $\mathrm{T}$ cells in the lymph nodes [37]. Therefore, redistribution of naive $\mathrm{T}$ cells to the lymphoid tissue does not seem likely. However, it has recently become clear that naive $\mathrm{T}$ cells may be compartmentalized early in life and can reside in many non-lymphoid tissues [38, 39]. Whether all these naïve $T$ cell populations in tissues are similarly affected by renal failure is not known.

The low thymic output may be directly related to an increased mortality, e.g. by a decreased immune response to new pathogens, or may act as a sensitive biomarker for an aged biological (immune) system. This is a highly relevant question as when the latter assumption holds true, rejuvenation of thymic function alone may not be sufficient to decrease mortality risk.

The number of naïve $T$ cells in elderly individuals has been linked to frailty and mortality $[40,41]$ although this was not found in all studies [42]. With regard to recipients of a renal transplantation low numbers of $\mathrm{CD} 4^{+} \mathrm{T}$ cells are associated with cardiovascular mortality [43] and opportunistic infection with Pneumocystis jiroveci pneumonia after transplantation [44]. In the latter study, it was noted that the lymphopenia was a relatively stable 
feature of the patients involved, confirming our observation that ESRD-related lymphopenia is not affected by renal transplantation. The current data, in accordance with previous studies, shows that ESRD-related lymphopenia is largely due to a loss of circulating naïve $\mathrm{T}$ cells. Therefore, the results of the above mentioned studies are most likely explained by the naïve $\mathrm{CD} 4^{+} \mathrm{T}$ cell lymphopenia which is underlying the total $\mathrm{CD} 4^{+} \mathrm{T}$ cell lymphopenia. In addition, the lower $\mathrm{CD}_{4}^{+} \mathrm{T}$ cell count in the deceased recipients groups lowers the $\mathrm{CD} 4 / \mathrm{CD} 8 \mathrm{~T}$ cell ratio which is therefore significantly associated with all-cause mortality. This is in accordance with the results of previous studies in healthy adults [45]. CMVseropositivity is a potential strong confounder of this association because of the CMV-infection associated increase in the CD8 $\mathrm{T}$ cells count [22] leading to a significantly decreased CD4/CD8 T-cell ratio. As the frequency of CMV seropositivity increases with age and is negatively related to socio-economic status, the CD4/ CD8 T-cell ratio as biomarker for mortality risk is highly susceptible for misinterpretation [30].

There are some obvious limitations to the current study that are worth mentioning. Our cohort of kidney transplant recipients all received a kidney of a living donor. This lead to a very homogenous cohort of recipients, not receiving $\mathrm{T}$ cell depletion therapy, almost no delayed graft function and excellent one-year patient and graft survival. In other transplantation programs, the majority of kidneys are from deceased donors and $\mathrm{T}$ cell depletion is regularly given as induction therapy. Therefore, the generalizability of the current findings is unknown at present. Another limitation is the relative low numbers of events (recipients deceased at follow up) limiting extensive multivariate analysis and allowing for confounders not identified.

\section{Conclusions}

A severely lowered number of circulating naïve $\mathrm{T}$ cells, indicative of a very low thymic output, before renal transplantation is not reversed by renal transplantation per se and is strongly associated with long term all-cause mortality.

\section{Methods}

\section{Study population}

All ESRD patients who received a kidney from a livingdonor in the period from November 1st 2010 to October 1st 2013 were considered for participation. Follow-up of patients included in the study was until November 2018.

All patients received a similar immunosuppressive regimen. This included induction therapy with basiliximab (Simulect ${ }^{\circ}$, Novartis) and maintenance therapy with tacrolimus (Prograf ${ }^{\oplus}$, Astellas Pharma), mycophenolate mofetil (Cellcept ${ }^{\oplus}$, Roche), and glucocorticoids. Clinical variables were assessed as shown in Table 1, including age, gender, CMV-seropositivity, number of prior renal transplantations, underlying cause of renal failure, preemptive RT. The primary end-point of the study was allcause mortality. Cause of mortality was documented as either cardiovascular disease, cancer, infectious disease, other and unknown. HLA-typing was performed according to the international standards (American Society for Histocompatibility and Immunogenetics/the European Federation for Immunogenetics) using serologic and DNA-based techniques. PRAs were determined at the laboratory of the blood bank in Leiden, the Netherlands.

\section{PBMC isolation}

By using Ficoll-Paque Plus (GE healthcare, Uppsala, Sweden), peripheral blood mononuclear cells (PBMC) were isolated from heparinized blood samples. Blood was drawn from RT-recipients the day before RT, and at 3, 6 and 12 months after RT. Isolated PBMCs were stored at $-150^{\circ} \mathrm{C}$ with a minimum amount of $10 \times 10^{6}$ cells per vial.

\section{T cell differentiation status and absolute numbers of $\mathrm{T}$ cell subsets}

To determine the T-cell differentiation status a whole blood staining was performed based upon a study by Sallusto et al. [46] as described in detail previously [4]. Naïve $\mathrm{T}$ cells were defined by the expression on either $\mathrm{CD} 4$ or CD8, CCR7 and the absence of CD45RO. Absolute numbers of the different $\mathrm{T}$ cell subsets were determined via a Trucount staining as described by Bouvy et al. [47].

\section{Statistics}

The difference between continuous variables was assessed with the Mann-Whitney U test. Normal distribution of data was assessed by the Shapiro-Wilk test of normality. Notnormal distributed data were represented in medians with interquartile range. The difference between categorical variables was analyzed either with the Pearson's chi-squared test or with the Fisher's exact test depending on the expected values in any of the cells of a contingency table. Cox proportional hazard analysis was used to assess the association between immunological parameters and the outcome all-cause death, including relevant clinical parameters (age, sex, preemptive transplantation, cardiovascular disease, C-reactive protein) in the model. Univariate Cox proportional hazards analysis was used to identify clinical and demographic variables associated with death at follow-up. Variables with a $p$ value of $\leq 0.1$ and sexe were considered for further analysis by multivariate logistic regression to calculate hazard ratios and corresponding confidence intervals. $\mathrm{PH}$ assumption of variables were tested by visual inspection of log-minuslog graphs and further tested by assessment of timedependency using the Cox regression with time-dependent covariate module in SPSS. All variables met the demands of $\mathrm{PH}$ unless stated otherwise. Interaction terms that met 
statistical significance $(p<0.05)$ were included in the multivariate model. Correlation matrices were made for the assessment of significant correlations. Absence of collinearity in the model covariates was formally assessed by calculating the variance inflation factor.

The significance level (p-value) was two-tailed and an $\alpha$ of 0.05 was used for all analyses. Statistical analyses were performed using $\mathrm{SPSS}^{\circ}$ version 21.0 for Windows ${ }^{\circ}$ (SPSS Inc., IL, USA) and GraphPad Prism 5 (CA, USA). Figures were created with GraphPad Prism 5 (CA, USA).

\section{Supplementary information}

Supplementary information accompanies this paper at https://doi.org/10. 1186/s12979-020-00175-Z.

Additional file 1: Table S1. Naïve T cell numbers before

transplantation in recipients stratified for CMV serostatus and survival after transplantation.

\section{Abbreviations}

CMV: Cytomegalovirus; ESRD: End-stage renal disease; RT: Renal transplantation; RTE: Recent thymic emigrant; TCR: T cell receptor

\section{Acknowledgements}

None.

\section{Authors' contributions}

MGHB participated in study design, data analysis and writing. AWL participated in study design and data analysis. MK: participated in data collection and data analysis. NHRL participated in study design, data collection and data analysis. All authors read and approved the final manuscript.

\section{Funding}

This study was supported by a grant of the Dutch Kidney Foundation (KSPB.10.12). The funding body had no role in the design of the study and collection, analysis, and interpretation of data and in writing the manuscript.

\section{Availability of data and materials}

All data generated or analysed during this study are included in this published article.

\section{Ethics approval and consent to participate}

All recipients and kidney donors (healthy controls) gave written informed consent to participate in the clinical trial and the immunological sub-study. The study was approved by the Medical Ethical Committee of the Erasmus MC (MEC number 2010-080, EudraCT 2010-018917-30) and conducted in accordance with the Declaration of Helsinki and the Declaration of Istanbul. All patients and kidney donors (healthy controls) gave written informed consent to participate in the clinical trial and the immunological sub-study. The study was approved by the Medical Ethical Committee of the Erasmus MC (MEC number 2010-080, EudraCT 2010-018917-30) and conducted in accordance with the Declaration of Helsinki and the Declaration of Istanbul.

\section{Consent for publication}

Not applicable.

\section{Competing interests}

The authors declare that they have no competing interests.

\section{Author details}

${ }^{1}$ Department of Internal Medicine, section Nephrology and Transplantation, Erasmus MC, University Medical Centre, Rotterdam, the Netherlands. ${ }^{2}$ Department of Immunology, Erasmus MC, University Medical Centre, Rotterdam, The Netherlands.
Received: 25 October 2019 Accepted: 2 February 2020

Published online: 13 February 2020

\section{References}

1. Betjes MG. Immune cell dysfunction and inflammation in end-stage renal disease. Nat Rev Nephrol. 2013:9:255-65.

2. Huang $L$, Betjes $M G H$, Klepper $M$, et al. End-stage renal disease causes skewing in the TCR Vbeta-repertoire primarily within CD8(+) T cell subsets. Front Immunol. 2017:8:1826.

3. Huang L, Langerak AW, Wolvers-Tettero IL, et al. End stage renal disease patients have a skewed T cell receptor Vbeta repertoire. Immun Ageing. 2015;12:28.

4. Betjes MG, Langerak AW, van der Spek $A$, et al. Premature aging of circulating T cells in patients with end-stage renal disease. Kidney Int. 2011;80:208-17.

5. Meijers RW, Betjes MG, Baan CC, et al. T-cell ageing in end-stage renal disease patients: assessment and clinical relevance. World J Nephrol. 2014;3:268-76.

6. Meijers RW, Litjens NH, de Wit EA, et al. Uremia causes premature ageing of the T cell compartment in end-stage renal disease patients. Immun Ageing. 2012;9:19.

7. Dedeoglu B, de Weerd AE, Huang L, et al. Lymph node and circulating $T$ cell characteristics are strongly correlated in end-stage renal disease patients, but highly differentiated T cells reside within the circulation. Clin Exp Immunol. 2017:188:299-310.

8. Chiu YL, Shu KH, Yang FJ, et al. A comprehensive characterization of aggravated aging-related changes in T lymphocytes and monocytes in endstage renal disease: the iESRD study. Immun Ageing. 2018;15:27.

9. Yoon JW, Gollapudi S, Pahl MV, et al. Naive and central memory T-cell lymphopenia in end-stage renal disease. Kidney Int. 2006;70:371-6.

10. Betjes MG, Meijers RW, Litjens NH. Loss of renal function causes premature aging of the immune system. Blood Purif. 2013;36:173-8.

11. Kruger $\mathrm{S}$, Muller-Steinhardt $\mathrm{M}$, Kirchner $\mathrm{H}$, et al. A 5-year follow-up on antibody response after diphtheria and tetanus vaccination in hemodialysis patients. Am J Kidney Dis. 2001;38:1264-70.

12. Girndt $M$, Pietsch $M$, Kohler $H$. Tetanus immunization and its association to hepatitis $B$ vaccination in patients with chronic renal failure. Am J Kidney Dis. 1995:26:454-60.

13. Litjens $\mathrm{NH}$, Huisman $\mathrm{M}$, van den Dorpel $\mathrm{M}$, et al. Impaired immune responses and antigen-specific memory CD4+ T cells in hemodialysis patients. J Am Soc Nephrol. 2008;19:1483-90.

14. Verkade MA, van de Wetering J, Klepper M, et al. Peripheral blood dendritic cells and GM-CSF as an adjuvant for hepatitis B vaccination in hemodialysis patients. Kidney Int. 2004:66:614-21.

15. Sarnak MJ, Jaber BL. Mortality caused by sepsis in patients with end-stage renal disease compared with the general population. Kidney Int. 2000;58:1758-64.

16. Dedeoglu B, Meijers RW, Klepper M, et al. Loss of CD28 on peripheral T cells decreases the risk for early acute rejection after kidney transplantation. PLoS One. 2016;11:e0150826.

17. Litjens NH, de Wit EA, Betjes MG. Differential effects of age, cytomegalovirus-seropositivity and end-stage renal disease (ESRD) on circulating T lymphocyte subsets. Immun Ageing. 2011;8:2.

18. Wikby A, Maxson P, Olsson J, et al. Changes in CD8 and CD4 lymphocyte subsets, T cell proliferation responses and non-survival in the very old: the Swedish longitudinal OCTO-immune study. Mech Ageing Dev. 1998;102:187-98.

19. Huppert FA, Pinto EM, Morgan $K$, et al. Survival in a population sample is predicted by proportions of lymphocyte subsets. Mech Ageing Dev. 2003; 124:449-51.

20. Wikby A, Johansson B, Olsson J, et al. Expansions of peripheral blood CD8 T lymphocyte subpopulations and an association with cytomegalovirus seropositivity in the elderly: the Swedish NONA immune study. Exp Gerontol. 2002:37:445-53.

21. Olsson J, Wikby A, Johansson B, et al. Age-related change in peripheral blood T-lymphocyte subpopulations and cytomegalovirus infection in the very old: the Swedish longitudinal OCTO immune study. Mech Ageing Dev. 2000;121:187-201.

22. Meijers RW, Litjens NH, Hesselink DA, et al. Primary Cytomegalovirus infection significantly impacts circulating T cells in kidney transplant recipients. Am J Transplant. 2015;15:3143-56.

23. Kohler S, Thiel A. Life after the thymus: CD31+ and CD31- human naive CD4+ T-cell subsets. Blood. 2009;113:769-74.

24. Ravkov E, Slev P, Heikal N. Thymic output: assessment of CD4(+) recent thymic emigrants and T-cell receptor excision circles in infants. Cytometry $B$ Clin Cytom. 2017;92:249-57. 
25. van den Broek T, Borghans JAM, van Wijk F. The full spectrum of human naive T cells. Nat Rev Immunol. 2018;18:363-73.

26. Kimmig S, Przybylski GK, Schmidt CA, et al. Two subsets of naive Thelper cells with distinct $T$ cell receptor excision circle content in human adult peripheral blood. J Exp Med. 2002;195:789-94.

27. Fagnoni FF, Vescovini R, Passeri G, et al. Shortage of circulating naive CD8(+) T cells provides new insights on immunodeficiency in aging. Blood. 2000;95: 2860-8.

28. den Braber I, Mugwagwa T, Vrisekoop N, et al. Maintenance of peripheral naive $T$ cells is sustained by thymus output in mice but not humans. Immunity. 2012;36:288-97.

29. Litjens NH, van Druningen CJ, Betjes MG. Progressive loss of renal function is associated with activation and depletion of naive T lymphocytes. Clin Immunol. 2006;118:83-91.

30. Betjes $M G$, de Wit EE, Weimar W, et al. Circulating pro-inflammatory CD4posCD28null T cells are independently associated with cardiovascular disease in ESRD patients. Nephrol Dial Transplant. 2010;25:3640-6.

31. Betjes MG, Litjens NH, Zietse R. Seropositivity for cytomegalovirus in patients with end-stage renal disease is strongly associated with atherosclerotic disease. Nephrol Dial Transplant. 2007;22:3298-303.

32. van de Berg PJ, Heutinck KM, Raabe R, et al. Human cytomegalovirus induces systemic immune activation characterized by a type 1 cytokine signature. J Infect Dis. 2010;202:690-9.

33. Simmons EM, Langone A, Sezer MT, et al. Effect of renal transplantation on biomarkers of inflammation and oxidative stress in end-stage renal disease patients. Transplantation. 2005;79:914-9.

34. Klein JB, McLeish KR, Ward RA. Transplantation, not dialysis, corrects azotemia-dependent priming of the neutrophil oxidative burst. Am J Kidney Dis. 1999;33:483-91.

35. Meijers RW, Litjens NH, de Wit EA, et al. Uremia-associated immunological aging is stably imprinted in the T-cell system and not reversed by kidney transplantation. Transpl Int. 2014;27:1272-84.

36. Dedeoglu B, Meijers RW, Klepper M, et al. Uremia-associated premature aging of T cells does not predict infectious complications after renal transplantation. Am J Transplant. 2016;16:2324-33.

37. Dedeoglu B, Litjens NHR, de Weerd AE, et al. T-cell composition of the lymph node is associated with the risk for early rejection after renal transplantation. Front Immunol. 2017:8:1416.

38. Thome JJ, Bickham KL, Ohmura Y, et al. Early-life compartmentalization of human $T$ cell differentiation and regulatory function in mucosal and lymphoid tissues. Nat Med. 2016;22:72-7.

39. Thome JJ, Grinshpun B, Kumar BV, et al. Longterm maintenance of human naive T cells through in situ homeostasis in lymphoid tissue sites. Sci Immunol. 2016;1.

40. Johnstone J, Parsons R, Botelho F, et al. T-cell phenotypes predictive of frailty and mortality in elderly nursing home residents. J Am Geriatr Soc. 2017;65:153-9.

41. Ferrando-Martinez S, Romero-Sanchez MC, Solana R, et al. Thymic function failure and C-reactive protein levels are independent predictors of all-cause mortality in healthy elderly humans. Age (Dordr). 2013;35:251-9.

42. Provinciali M, Moresi R, Donnini A, et al. Reference values for CD4+ and CD8+ T lymphocytes with naive or memory phenotype and their association with mortality in the elderly. Gerontology. 2009;55:314-21.

43. Ducloux D, Courivaud C, Bamoulid J, et al. Prolonged CD4 T cell lymphopenia increases morbidity and mortality after renal transplantation. J Am Soc Nephrol. 21:868-75.

44. Struijk GH, Gijsen AF, Yong SL, et al. Risk of Pneumocystis jiroveci pneumonia in patients long after renal transplantation. Nephrol Dial Transplant. 2011;26:3391-8.

45. Wikby A, Mansson IA, Johansson B, et al. The immune risk profile is associated with age and gender: findings from three Swedish population studies of individuals 20-100 years of age. Biogerontology. 2008;9:299-308.

46. Sallusto F, Lenig D, Forster $R$, et al. Two subsets of memory T lymphocytes with distinct homing potentials and effector functions. Nature. 1999;401:708-12.

47. Bouvy AP, Kho MM, Klepper M, et al. Kinetics of homeostatic proliferation and thymopoiesis after rATG induction therapy in kidney transplant patients. Transplantation. 2013;96:904-13.

\section{Publisher's Note}

Springer Nature remains neutral with regard to jurisdictional claims in published maps and institutional affiliations.

Ready to submit your research? Choose BMC and benefit from:

- fast, convenient online submission

- thorough peer review by experienced researchers in your field

- rapid publication on acceptance

- support for research data, including large and complex data types

- gold Open Access which fosters wider collaboration and increased citations

- maximum visibility for your research: over $100 \mathrm{M}$ website views per year

At BMC, research is always in progress.

Learn more biomedcentral.com/submissions 